\title{
HIV Quadruple Limb Gangrene: An Unusual Presentation and Review of Literature
}

\author{
Edwin Omon Edomwonyi*, John Enekele Onuminya, Alfred Oghogho Ogbemudia, \\ Osita Chizoba Nwokike, Emeka Blessius Kesieme \\ Department of Orthopaedics and Traumatology, Irrua Specialist Teaching Hospital, Irrua, Nigeria \\ Email: *edwinedomwonyi@rocketmail.com
}

Received August 7, 2013; revised August 28, 2013; accepted September 3, 2013

Copyright (C) 2013 Edwin Omon Edomwonyi et al. This is an open access article distributed under the Creative Commons Attribution License, which permits unrestricted use, distribution, and reproduction in any medium, provided the original work is properly cited.

\begin{abstract}
Vasculitis is one of the less common but important consequence in patients with Human Immunodeficiency Virus (HIV) infections and presentation with multiple limb gangrene is rare. We therefore report a novel case of quadruple limb gangrene in a patient with HIV infection.
\end{abstract}

Keywords: HIV; Quadruple Limb Gangrene; Presentation; Amputation; Irrua

\section{Introduction}

Quadruple limb gangrene associated with HIV infection is rare. The common aetiologies of gangrene of the limbs are trauma, diabetes mellitus and artherosclerosis [1]. However, systemic lupus erythematosus, progressive sclerosis, henoch scholein syndrome, takayasu arteritis, antineutrophil cystoplasmic antibody (ANCA) associated vasculitis, gangrene associated with procoagulant states due to malignancy, and anticardiolipin antibody syndrome are some important causes of gangrene of the extremities. Rare causes of gangrene include heparin induced thrombocytopenia (HIT), hemolytic uremic syndrome (HUS) and Human immunodeficiency virus (HIV) infection [2].

HIV infection is multisystemic, and cardiovascular involvement is not an exception. It may present with arterial occlusive disease, aneurismal disease, aortic dissection or AV fistula [2,3]. Vasculitis is one of the less common but important consequences of HIV. Peripheral arterial disease (PAD) is more prevalent in the HIVinfected population than in the general population. Widespread digital ischaemic changes and gangrene of the hands and feet are uncommon in patients with HIV infection [2-7]. A few cases of one or two limb gangrene associated with HIV infection have been reported from other centres [2-10]. The only reported case of quadruple limb amputation reported in our environment was due to trauma [1].

\footnotetext{
"Corresponding author.
}

Quadruple gangrene of the extremities associated with HIV infection is therefore reported to highlight the rare complication and challenges. Relevant literature is also reviewed.

\section{Case Report}

A 28-year-old southern lady presented wounds in both upper and lower limb of two months duration via the Accident and Emergency department of Irrua Specialist Teaching Hospital, Irrua. She was in her usual state of health until 6 months prior to presentation when she developed pepperish/tingling sensations on both upper and lower limbs. She wasn't a known hypertensive or diabetic. Subsequently, she noticed that the feet became swollen and later ulcerated. She sought help in a native herbal home where topical herbal preparation was applied on scarification marks. Three months later, darkening of the toes was noticed which gradually spread to both feet with loss of sensation. A month later, a similar process repeated itself in both upper limbs following the same chronology.

The husband was a long distant driver who abandoned her in the course of the ailment claiming he does not understand the nature of the ailment. She never smoked cigarette, ingest tobacco. No past history of suggestive of coronary disease or stroke. On examination, we saw an emanciated young lady in mild painful distress. She was pale with bilateral inguinal lymphadenopathy. Nil axillary lymph node enlargement. Vitals were within normal range. She was hemodynamically stable. Abdomen and 
Respiratory systems were essentially normal.

Extremities were darkish in colour and withering of both hands and feet. The clinical appearances of the quadruple gangrene of the feet and hands are shown in Figures 1((a)-(c)). Feet were almost severed at the ankle joints exposing the ligament, tendons and bones with offensive discharge. Sensory loss in both feet was up to the distal third. Dorsalis pedis and posterior tibial arterial pulsations were absent. Popliteal arterial pulsation felt but faint.

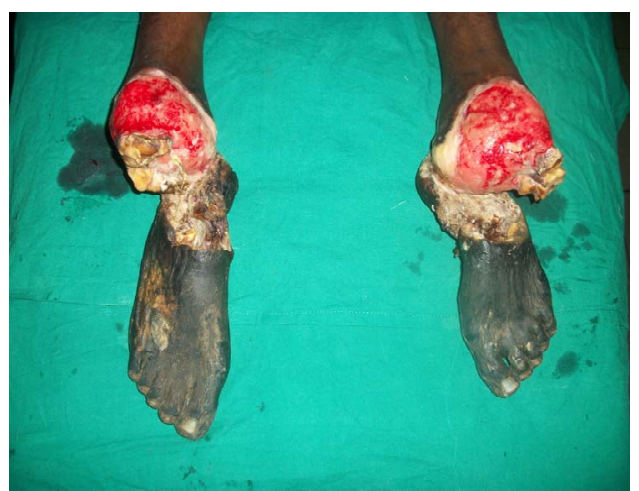

(a)

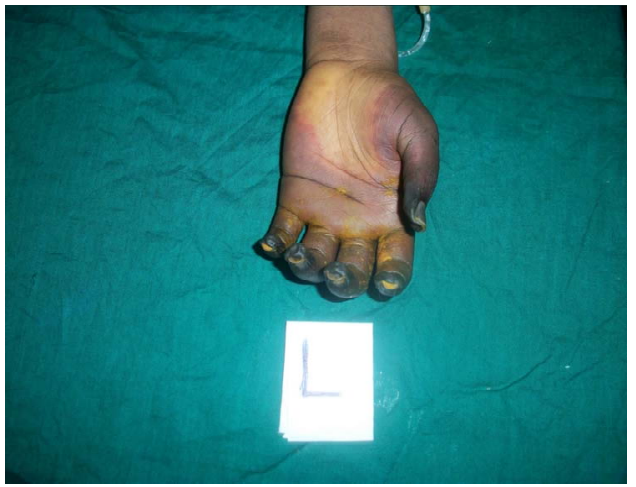

(b)

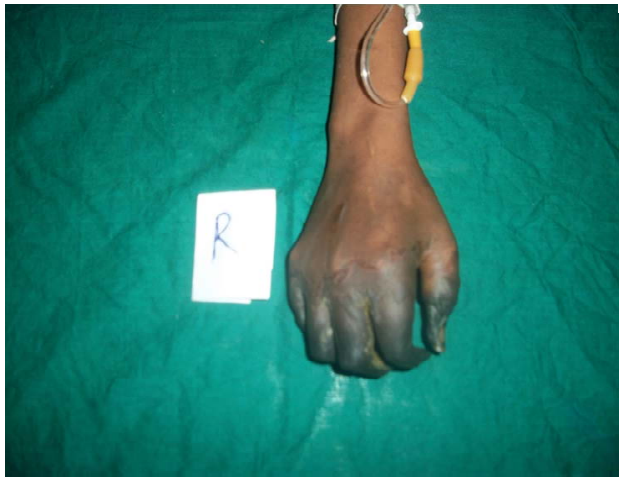

(c)

Figure 1. Clinical appearances of the quadruple gangrene of feet and hands: (a) Gangrene of the feet with autodisarticulation at the ankle joints from a traditional surgeon's home; (b) Gangrene of the left hand; (c) Gangrene of the right hand.
There was hyperpigmentation of both hands up to the metacarpophalangeal joints, and the metacarpophanlangeal joints were in fixed flexion deformity with sensory loss. Radial arterial pulsation was present in both upper limbs. RBS was $86 \mathrm{mg} / \mathrm{dl}$, Pcv was 27\%, total Wbc, 4600 c/mm $\mathrm{mm}^{3}$; Platelet, 397,000 c/ $\mathrm{mm}^{3}$; Na $140 \mathrm{mmole} / \mathrm{l}$, K 2.9 mmole/l, Cr 0.8, CD4 count was $324 \mathrm{cl} / \mathrm{ul}$. While she was being worked up for emergency surgery it was discovered she was HIV positive.

Emergency bilateral BKA were done under GA. Two weeks later bilateral BEA was done on both upper limbs. Lower limbs wounds were discovered to be infected and this was managed by regular povidone iodine wound dressing and antibiotics. The medical team also assessed her and commenced HAART, lamivudine, nevirapine, zidovudine as well as hematinics.

Wound cleaned out and refashioning of stumps were done at intervals and wounds healed satisfactorily. Post operative period was largely uneventful. Majority of other requested investigations (Doppler USS, lipids etc.) were not done due to financial constraints. The Management of the hospital wrote off the bill and was finally discharged after 114 days on admission without prostheses owing to lack of fund.

\section{Discussion}

Peripheral vascular disease is a common indication for amputation of patients in the developed world and the reverse is the case in Nigeria where traumas and diabetes lead [1].

Peripheral artery disease is more prevalent in the HIV infected population than in the general population and there is a six fold increased risk for Peripheral artery disease in the HIV infected individuals as well as an earlier onset of the disease compared with HIV negative patients [9].

Almost every pattern and type of vasculitis of small, medium and large vessels has been encountered in HIV setting [3]. Widespread digital ischemic changes and gangrene of the hands and feet is one uncommon presentation in patients with HIV infection [8], which makes this case stand out.

HIV positive patients with vasculopathy are younger with an average age of 40 yrs in comparison to 55 yrs in patients with artherosclerotic disease [3]. This is in support of our case who was 28 yrs of age. HIV associated vascular disease is a specific disease entity which differs from artherosclerotic disease in many aspects. Risk factors for artherosclerosis like smoking, hypertension and diabetes mellitus are lower in incidence among patients with HIV than peripheral vascular disease. This patient never smoked. She was neither hypertensive nor diabetic.

CD4 T cell count 200 cells/ul was found as a significant predictor of peripheral artery disease in HIV [9]. As 
shown in this case CD4 count of patients with HIV vasculopathy are less than normal in 90\% and the CD4/CD8 ratio is usually reversed, indicated of advanced Immunosuppression [3]. Infection, occlusive disease due to hypercoagulable states, vasculitis is some of the mechanisms suggested for gangrene of the extremities in HIV.

Psychiatric symptoms complicating amputation is not out of place as noticed in our patient, the physical reality of mutilation, body image changes and diagnosis of HIV in a patient is strong enough stress.

Risk of HIV was obvious in this patient; the husband being a long distance driver who even neglected the patient when she became ill. She was seriously handicapped financially. Hence, she was unable to do most investigation and her bills had to be written off after several weeks of neglect following discharge from hospital.

\subsection{Etiology of Gangrene in HIV}

Vasculitis, occlusive disease and infections, hypercoagulable states. Deficiency of protein $\mathrm{C}$ and free protein $\mathrm{S}$, antiThrombin III. Anti phospholipid syndrome have been implicated as mechanism. Antiretroviral medications could lead to endothelial damage too.

\subsection{Clinical Feature}

1) Male preponderance for obscure reasons; 2) Rest pain of the limbs from ischemia; 3) Intermittent claudication Gangrene.

\subsection{Diagnosis}

HIV associated gangrene may be associated with a known pathogen or trigger or may occur in the absence of one. To determine this, either a serological test, staining of smears, light microscopy, culture, immunohistochemistry testing and viral markers may be done depending on the clinical presentation.

Work up for protein C, S, antithrombin III, antinuclear antibodies, antiphospholipid antibodies. Ankle index (AB1) testing would help to identify those with Peripheral vascular disease.

Doppler study of the vascular system is essential. Spotting within the arterial wall test described as string of pearl sign [3].

Diagnostic angiography would identify the location of occlusive or aneurysm. Care should be taken to heparinize these patients before the procedure because of the high risk of thrombosis.

\subsection{Management}

HIV vasculopathy and gangrene represent an advanced stage of the disease process. It is advisable to commence HAART irrespective of the CD4 count.
Patients with unsalvageable limb should have primary amputation. When limb is salvageable, treatment options include endovascular procedure like thrombectomy, thrombolysis or by-pass procedures. Limb salvage rate has been in the region of $27 \%$ [3]. Widespread ischemic necrosis and gangrene may require treatment with corticosteroids (in the event of vasculitis), thrombolytic agents (for thrombotic component), or both. Vascular surgical principles should be adhered to and management should be individualized. When patients present late with gangrene as in the index case amputation is the option of surgical treatment and in this case the morbidity was high. The challenges were multiple in every respect.

\section{Conclusions}

Quadruple limb gangrene associated with HIV infection is a rare and novel report from Irrua. In the light of the foregoing, this is a wakeup call for clinicians. Clinicians should consider HIV as an important cause of limb gangrene and screen for presence of HIV antibodies while evaluating a patient with non-traumatic limb gangrene.

Early detection and timely commencement of appropriate treatment may prevent vascular complication and subsequent gangrene in asymptomatic patients.

\section{REFERENCES}

[1] J. E. Onuminya, P. O. Obekpa, H. C. Ihezue, N. D. Ukegbu and B. O. Onabowale, "Major Amputation in Nigeria: A Plea to Educate Traditional Bone Setters," Tropical Doctor, Vol. 30, No. 3, 2000, pp. 133-135.

[2] V. S. S. Malladi, S. Abkari and V. R. Srinivasan, "Gangrene Associated with HIV,” In: A. Vigin, Ed., Current Concepts and Management Options, InTech, 2011, pp. 105-112. www.intechopen.com

[3] T. V. Malaudzi, J. V. Robbs, W. Pillay, et al., "Thromectomy in HIV Related Peripheral Arterial Thrombosis: A Preliminary Report," European Journal of Vascular and Endovascular Surgery, Vol. 30, No. 1, 2005, pp. 102-106.

[4] A. L. Rakrani, A. Basavraj and R. Madraki, "Vasculitis with Digital Gangrene in a Patient with HIV Infection," Journal of the Association Physicians of India, Vol. 51, 2003, pp. 299-301.

[5] M. W. Saif, R. Bona and B. Greenberg, "AIDs and Thrombosis: Restrospective Study of 131 HIV-Infected Patients,” AIDs Patient Care and STDs, Vol. 15, No. 6, 2001, pp. 311-320. http://dx.doi.org/10.1089/108729101750279687

[6] D. Demopoulos, W. Hendson, K. Technau, et al., "Vasculopathy in HIV-Infected Children-A Case Series," SA Journal of Child Health, Vol. 3, No. 1, 2009, pp. 27-30.

[7] Y. K. Ye; Y. Zeng; X. M. Li, et al., "HIV Infection: An Independent Risk Factor of Peripheral Artery Patient," Journal of Acquired Immune Deficiency Syndromes, Vol. 53, No. 2, 2010, pp. 276-278. http://dx.doi.org/10.1097/QAI.0b013e3181ba1c31 
[8] J. V. Robs and N. Paruk, "Management of HIV Vasculopathy-A South African Experience,” European Journal of Vascular and Endovascular Surgery, Vol. 39, No. S1, 2010, pp. S25-S31.

[9] D. Periard, M. Casvassini, P. Taffe, et al., "High Prevalence of Peripheral Artery Disease in HIV-Infected Per- sons,” Clinical Infectious Diseases, Vol. 46, No. 5, 2008, pp. 761-767.

[10] L. Scholtz, "Vascular Manisfestations of HIV/AIDs," Cardiovascular and Interventional Radiology, Vol. 27, No. 5, 2004, pp. 422-426. 